
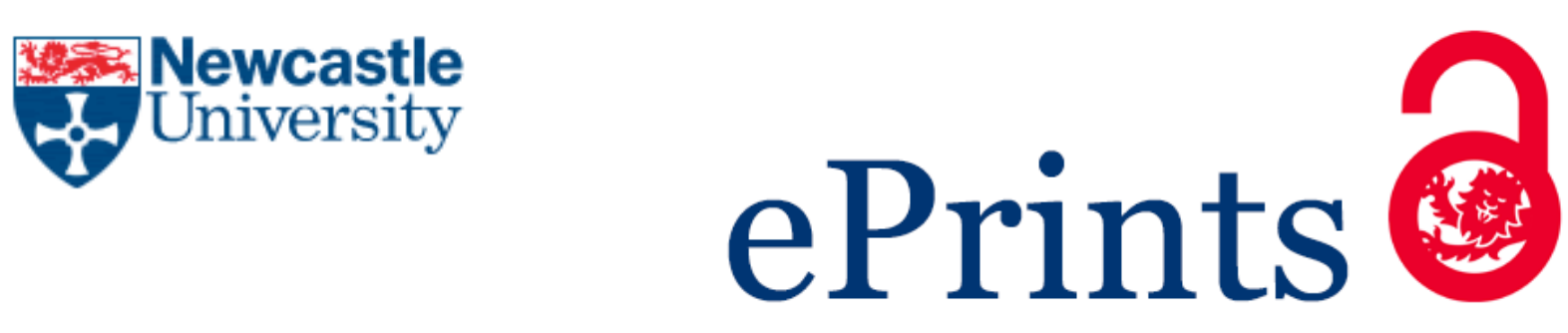

Alkanderi S, Yates LM, Johnson SA, Sayer JA.

Lessons learned from a multidisciplinary renal genetics clinic.

QJM 2017, 110(7), 453-457.

\title{
Copyright:
}

This is a pre-copyedited, author-produced version of an article accepted for publication in QJM following peer review. The version of record is available online at: https://doi.org/10.1093/qjmed/hcx030

Date deposited:

$11 / 09 / 2017$

Embargo release date:

08 February 2018 


\section{Lessons learned from a multidisciplinary renal genetics clinic}

3 Sumaya Alkerandi ${ }^{1}$, Laura Yates ${ }^{1,2}$, Sally Johnson ${ }^{3}$ and John A. Sayer ${ }^{1,4}$

4

$5 \quad{ }^{1}$ Institute of Genetic Medicine, Newcastle University, Central Parkway, Newcastle NE1 3BZ,

6 U.K

$7 \quad{ }^{2}$ Northern Genetics Service, International Centre for Life, Central Parkway, Newcastle NE1

8 3BZ, U.K.

$9 \quad{ }^{3}$ Royal Victoria Infirmary, Newcastle, NE1 4LP , U.K.

$10{ }^{4}$ Renal Services, Newcastle upon Tyne NHS Foundation Trust Hospitals, Newcastle upon Tyne 11 NE7 7DN, U.K.

\section{Abstract}

Background. Inherited renal disorders comprise a significant proportion of cases in both paediatric and adult nephrology services. Genetic advances have advanced rapidly whilst clinical models of care delivery have remained static.

Aim. To describe a cohort of patients attending a multidisciplinary renal genetics clinic and the insights gained from this experience.

22 Design and Methods. A retrospective review of clinic cases and their molecular genetic diagnosis over a five year period.

24 Results. We report details of 244 individuals including 80 probands who attended the clinic. The commonest reasons for referral was familial haematuria which accounted for $37.5 \%$ of cases and cystic kidney disease, accounting for $31 \%$ of cases. 18 probands had a known molecular genetic diagnosis and were referred for genetic counselling and screening of at risk

28 relatives and management plans. 62 probands and their families were referred for a precise molecular diagnosis and this was achieved in 26 cases (42\%). The most frequent new genetic diagnoses were COLAA5 mutations underlying familial haematuria and familial end stage renal disease. The clinic also allowed for patients with rare renal syndromes to be reviewed, such as ciliopathy syndromes, allowing detailed phenotyping and often a precise molecular genetic diagnosis to be provided. 
1 Conclusions. The integration of modern day genetics and genomics into multidisciplinary 2 clinics often allows a precise diagnosis which benefits patients, their relatives and the clinicians 3 providing care and future management.

4 


\section{Introduction}

3 Inherited renal diseases are a significant cause of chronic kidney disease (CKD) and end stage renal disease (ESRD) in both adult and paediatric populations. The causes of ESRD in children include renal tract malformations in around $35 \%$ of cases ${ }^{1}$, congenital nephrotic syndrome in $10 \%$ and cystic kidney disease in $5 \%$. It is becoming clearer that variants in genes encoding transcription factors important for renal development (and maintenance) such as WT1, PAX2 and $H N F 1 B$ may lead to both renal tract malformations and renal syndromes with significant extra-renal features ${ }^{2,3}$. Genetic renal tract disorders also contribute to a significant (and probably under-diagnosed) proportion of later-onset (adult) ESRD. Awareness and recognition of inherited renal disorders and the documentation of detailed family history are vital factors to ensure a genetic diagnosis is not missed ${ }^{4}$. Within reported cohorts of adults with kidney disease, autosomal dominant polycystic kidney disease (ADPKD) is the commonest monogenic genetic cause ${ }^{5,6}$, accounting for $\sim 10 \%$ of ESRD in the $\mathrm{UK}^{7}$ whilst other forms of cystic kidney disease are rare. Inherited collagenopathies, including Alport syndrome, are being increasingly recognised as a cause of adult onset kidney disease. Mutations in the COLA genes account for Alport syndrome and familial haematuria syndromes and are one of the commonest causes of familial focal segmental glomerulosclerosis (FGSG) ${ }^{8}$.

Timely and early recognition, diagnosis and management of these forms of kidney disease is therefore extremely important. Through a close working relationship between clinical genetics and both adult and paediatric nephrology we have developed a multidisciplinary renal genetics clinic for families and patients in whom a genetic renal disorder was suspected. Here we report a five-year review of the case load, as part of a registered audit adhering to local guidelines and discuss clinical benefits and impact of this multi-specialty clinic, based in the north east of England.

Results

In 2007 a multidisciplinary renal genetics clinic was established within the Renal Services Department, Freeman Hospital, Newcastle upon Tyne Hospitals NHS Foundation Trust. Our aim was to provide genetic diagnosis to guide management, screening and counselling of 
1 families with inherited renal disorders in response to a clinical need. The multidisciplinary 2 clinic design allowed a clinical geneticist, an adult nephrologist (with a special interest in renal genetics) and a paediatric nephrologist to see families together within the same clinic room.

4 We hosted the clinic every 3 months. Genetic testing was performed largely using targeted single gene tests and small panels available through the UK Genetic Testing Network 6 (UKGTN, http://ukgtn.nhs.uk/), with occasional testing undertaken in a research basis. 7 Typically, probands and their family members were seen just once within this multidisciplinary 8 setting and appropriate follow up with individual clinicians was arranged for subsequent visits.

From 2007-2011 a total of 244 individuals, comprising 80 probands, 50 affected relatives and 114 unaffected relatives were reviewed within this multidisciplinary clinic. The number of family members ranged from 1 to 7 members in total, with a mean of $\sim 3$. The mean age of the probands at time of referral was $\sim 19$ years. Ages ranged from new-born children to adults 57 years of age. 50 probands $(62.5 \%)$ were less than 18 years of age at their clinic review. The vast majority of probands were white Europeans, with no known consanguinity, with only 6 probands of Asian origin, two of whom were from consanguineous families.

Referrals were mostly from paediatric nephrology services, accounting for 56 of the 80 probands, with the remainder from adult nephrology (14) clinical genetics (3), primary care (4), surgery (2) and oncology (1). The clinic was designed to be a tertiary referral centre and attracted patient referrals from the whole of the north of England. Patients attended from as far as Scarborough (99 miles) and Cumbria (98 miles). The mean distance of travel to the clinic for each family who attended was 22 miles.

The most common reasons for referral were for investigation of a suspected familial haematuria (often with proteinuria and associated with CKD and ESRD) or for investigation and diagnosis of a possible inherited cystic kidney disease (Table 1). 18 of the probands had a known genetic diagnosis with pathogenic or likely pathogenic mutations prior to referral (Table 2). These patients and their families were referred for genetic counselling and information prior to clinical, biochemical and genetic screening as well as disease management and prognosis in light of genetic results. The remaining 62 probands had an unknown or imprecise clinical diagnosis and were referred to clarify both a clinical and molecular genetic diagnosis. 
1 Of the 62 cases referred for a more precise molecular genetic diagnosis, this was provided in 226 cases (42\%). Molecular genetic diagnoses made following the clinic (Table 3) included 3 COL4 associated disease in 16 probands. There were no common or founder mutations 4 identified within this cohort, which was perhaps unexpected in this very stable population. In 5 almost every case genetic testing identified pathogenic changes that had been previously 6 reported or novel changes with predicted pathogenicity. In one proband molecular testing 7 identified a COLAA5 variant of uncertain significance. Here segregation of the variant was performed to allow clinical phenotypes to be correlated with this genotype. RNA studies were not routinely carried out but we anticipate, with wider genetic testing (using panels, whole exome and whole genome approaches) such additional studies will be required to confirm pathogenicity of splice-site mutations and other intronic changes predicted to affect splicing.

13 Nine probands remained without a molecular diagnosis, despite targeted genetic testing of candidate genes available through UKGTN at the time. These cases included familial haematuria (4), congenital anomalies of the kidney and urinary tract (CAKUT) (1), renal cystic disease (2), early onset hypertension (1) and a suspected ciliopathy (1). Several of these probands and their relatives who remained genetically unsolved, were subsequently recruited to the Newcastle pilot study of the Genomics England 100,000 Genomes Project (https://www.genomicsengland.co.uk/) for more detailed genetic studies.

Novel insights from the clinic

The combined family clinic was a valuable setting in which to take time to explore renal and extra renal phenotypes and to consider rare diagnoses. Excluding cases of ADPKD, which is commonly associated with the extra renal manifestation of liver cysts, there were extra renal manifestations present in 25 of the cases, pointing to rare syndromes. These included deafness (in 6 probands), gout, liver fibrosis, skeletal abnormalities and retinal defects. One family, which we have previously reported ${ }^{9}$, presented with an autosomal dominant pattern of progressive renal failure comprising renal dysplasia (CAKUT) and a history of eye disease. A renal coloboma syndrome was suspected. Ophthalmological examination revealed optic nerve colobomas and mutation analysis subsequently confirmed $P A X 2$ mutations segregating with 
1 renal and eye phenotypes. Establishing a genetic diagnosis within this family helped to identify other at risk family members who could be screened for mutations. Those who were mutation positive could be investigated appropriately with renal and ophthalmological testing, but avoiding invasive tests such as renal biopsies. It is worth noting that the complications of renal biopsy may be serious and include bleeding requiring transfusion (0.9\%), angiographic intervention $(0.6 \%)$ and rarely nephrectomy $(0.01 \%)^{10}$. The risk of fatality following renal biopsy is small $(0.02 \%)$ but real ${ }^{10}$.

In another family, we were able to diagnose CEP290 mutations as a cause of a retinal-renalcerebellar syndrome (Joubert syndrome) who presented with visual loss, cystic kidney disease and rapidly declining renal function. Establishment of a precise diagnosis allowed focused investigations, avoided renal biopsy and allowed decision making on family planning and renal transplantation.

The diagnosis of a truncating PKD1 mutation was made in one family whose child presented with a febrile illness at 8 weeks of age prompting a renal USS, which was diagnostic for ADPKD. However, both parental renal USS were normal, suggesting a de novo mutation in this family, which was confirmed on molecular genetic testing. The importance of a precise diagnosis of inherited cystic kidney disease cannot be emphasized enough. Autosomal dominant polycystic kidney disease (ADPKD) is common, and should be easily recognised ${ }^{11}$. However, in around $1 \%$ of cases it may present with cystic kidney disease at birth and the diagnosis may be confused with other congenital cystic diseases. Typical extra renal features of ADPKD include liver cysts and intracranial aneurysm formation. ADPKD does however have its mimics and mutations in $H N F 1 B, O F D 1$ and $T S C 1 / 2$ can phenocopy the cystic kidney disease phenotype ${ }^{12}$. In this cohort we did not routinely screen for PKD1 and PKD2 mutations in cases of cystic kidney disease but reserved these tests where there was true diagnostic uncertainty or a pressing clinical need, such as very early onset disease or a molecular diagnosis was essential for reproductive decisions, in accordance with UKGTN guidelines. We made a new molecular genetic diagnosis of PKD1 mutation in 4 families, 2 of whom the proband were paediatric presentations of cysts. In each of these families, this molecular diagnosis has allowed other family members considering live-donor kidney transplantation to be genetically screened. Recent increased availability of such genetic tests will allow these tests to be undertaken more readily to allow a precise diagnosis, which is often needed for planning live-related kidney 
1 years of age. An early (childhood) diagnosis of ADPKD may allow the detection and treatment of hypertension and the early use of disease modifying drugs (within clinical trials) such as tolvaptan.

The most frequent reason for referral was suspected familial haematuria and the most common molecular diagnosis of COL4 mutations reflected this. We identified families with X-linked, autosomal dominant and autosomal recessive COLA disease. An extended pedigree diagram which included the presence of deafness, haematuria, proteinuria and ESRD helped to determine the likely pattern of inheritance, which was then confirmed at the molecular genetic basis. Patients with suspected COL4 mutations were sent for formal audiology and ophthalmological examinations.

The Newcastle clinic is not unique in the UK. A similar model in London, with an emphasis on paediatric renal malformations has been previously reported ${ }^{13}$. There are also multidisciplinary renal genetics clinics in Cambridge and Manchester. The emphasis on a genetic diagnosis and appropriate counselling, investigation and treatment of families in a multidisciplinary setting is a shared aim. Various combinations of consultants in nephrology, paediatrics, genetics and urology can be brought together to provide an environment of excellence to allow rare renal diseases to be managed appropriately. A multidisciplinary renal genetics clinic experience has been recently reported from Australia ${ }^{14}$ where molecular genetic testing confirmed a diagnosis in about half the cohort and allowed a change in diagnosis in a around a quarter of the referred cases. Multidisciplinary genetics clinics are applicable to many medical specialities and in our view will be increasingly required to bridge between advances in genetics and genomics and clinical medicine to allow the diagnosis and management of inherited disease.

Our clinic experience has helped us to identify certain take away messages. These include the ability to, when seeing whole families together, identify variable phenotypes and incomplete penetrance within families. This observed variability illustrates the complexities of monogenic inherited diseases and the intricacies of genetic counselling and predicting long term prognosis for patients with risk alleles. There is also a holistic benefit of seeing family members together. Advice and management plans can be given to the whole family, avoiding the mixed messages that family members may receive when seeing different medical professionals in isolation. This 
1 also facilitates a provision of balanced and consistent advice to the referring physician and the 2 primary care physician which can be executed locally, as required.

4 We also observed a broadening of previously described phenotypes, this was especially true 5 for patients with ciliopathy syndromes. A clear advantage of the clinic was the ability to collect 6 accurate phenotypic information at the same time as collecting DNA samples in multiple 7 family members to allow testing of the most appropriate / informative individual and then allow cascade screening to proceed in an effective manner. This approach also allows variants of uncertain significance identified in a proband to be tested for segregation with disease phenotypes in other family members.

We have also valued the opportunity to discuss novel therapies (often with the emphasis on personalised medicine approaches) with families and involve them in active research projects and rare disease programmes (such as The National Registry of Rare Renal Disease (RaDaR) www.rarerenal.org).

The cost of genetic testing is an important consideration for any genetics clinic. Multidisciplinary clinics in themselves are costly, without the addition of expensive genetic tests. In the UK, costs of individual gene tests do remain disproportionately high compared to large panel and whole exome sequencing approaches. Whole genome sequencing with virtual gene panels to allow filtering of sets of genes to certain phenotypes will hopefully become part of routine NHS care in the UK following the vision of Genomic England's 100,000 Genomes Project. The integration of lessons learnt from such approaches with UKGTN's expanding portfolio will hopefully allow a more cost effective diagnostic genetic service to be developed. The economic case for performing a panel gene test, whole exome or even whole genome sequencing test in patients with rare disease and undiagnosed disease should now be easily accepted ${ }^{15}$. Cost effectiveness analysis data from diagnostic genetic clinics has recently been reported ${ }^{16,17}$. Before a genetic diagnosis patients are often seen by multiple clinicians and have multiple expensive and often invasive investigations. As an example, the cost of performing a gene panel test for familial haematuria in a proband and the additional cost for screening of variants in at risk family members can be offset against multiple investigations that may be carried out among multiple members of the same family. Tests such as cystoscopies and renal biopsies are frequently performed in order to secure a diagnosis, often without any co-ordination between family members or their clinicians. 
2 The power of securing a molecular genetic diagnosis in a large family of affected patients and at risk relatives reduces the need for invasive, costly and often unnecessary investigations (such as percutaneous renal biopsy and cystoscopy) in multiple relatives. These clinical and radiological investigations, as well as being expensive, can be stressful, given their lack of 6 diagnostic precision.

\section{Conclusions}

The power of a precise diagnosis is increasingly important, valued and achievable. Families have often seen many doctors and specialists and have not been offered a unifying diagnosis. There is a palpable and real benefit for both the patients and their physicians in securing a molecular genetic diagnosis. There is almost certainly a health economic value of ending the diagnostic odyssey for patients with genetic and often rare disease. It allows, within the clinic or follow up clinics, an opportunity to explain mechanisms of disease, explain risks of progression of renal disease and risk of extra renal manifestations. Lifestyle changes can be made with more positivity once a firm diagnosis is established. A precise diagnosis in a paediatric nephrology patient will hopefully ensure a more planned transition into adult nephrology services. The long term study of cohorts of patients with inherited disease will allow clinicians to learn more about disease progression and outcomes, which in turn will help families who are desperate to learn more about the implications of their inherited disease. Furthermore, having a precise genetic diagnosis allows the identification of at risk relatives and contributes in family planning decisions through assisted reproductive medicine. The multidisciplinary approach maximizes the use of time for the patients and the physicians. The future vision, which has been cast by Genomics England is to allow genomic medicine to permeate throughout the NHS to allow efficient and precise molecular diagnoses to inform clinical care. Such genomic medicine programs are not without their obstacles but the benefits may be huge ${ }^{18}$. Certainly a move away from individual gene tests to panel, exome and genome approaches will allow a more thorough and cost effective genetic analysis, and the UKGTN's expanding portfolio (http://ukgtn.nhs.uk/) confirms the utility of such approaches. Genetic testing alone is meaningless without precise phenotyping data and the ability of astute clinicians to provide this should never be disregarded. We firmly believe our multidisciplinary approach to renal genetic provides added value and improves patient diagnosis and care. 
2

3

4

5

6 Acknowledgements

7

8 JAS is supported by Northern Counties Kidney Research Fund and the Medical Research

9 Council (MR/M012212/1).

10 


\section{References}

4

1. Pruthi R, Hamilton AJ, O'Brien C, Casula A, Braddon F, Inward C, et al. UK Renal Registry 17th Annual Report: Chapter 4 Demography of the UK Paediatric Renal Replacement Therapy Population in 2013. Nephron. 2015;129 Suppl 1:87-98.

2. Thomas R, Sanna-Cherchi S, Warady BA, Furth SL, Kaskel FJ, Gharavi AG. HNF1B and PAX2 mutations are a common cause of renal hypodysplasia in the CKiD cohort. Pediatr Nephrol. 2011;26:897-903.

3. Adam J, Browning AC, Vaideanu D, Heidet L, Goodship JA, Sayer JA. A wide spectrum of phenotypes in a family with renal coloboma syndrome caused by a PAX2 mutation. Clinical Kidney Journal. 2013;6:410-3.

4. McCloskey S, Yates L, Sayer JA. The importance of taking a family history in the nephrology clinic. British Journal of Renal Medicine. 2016;21:38-42.

5. $\quad$ https://www.usrds.org/ 2016 [cited 2016 28/11/2016].

6. $\quad$ http://www.anzdata.org.au/ 2016 [cited 2016 28.11.2016].

7. Gilg J, Pruthi R, Fogarty D. UK Renal Registry 17th Annual Report: Chapter 1 UK Renal Replacement Therapy Incidence in 2013: National and Centre-specific Analyses. Nephron. 2015;129 Suppl 1:1-29.

8. Gast C, Pengelly RJ, Lyon M, Bunyan DJ, Seaby EG, Graham N, et al. Collagen (COL4A) mutations are the most frequent mutations underlying adult focal segmental glomerulosclerosis. Nephrol Dial Transplant. 2015.

9. Adam J, Browning AC, Vaideanu D, Heidet L, Judith A G, Sayer JA. A wide spectrum of phenotypes in a family with renal coloboma syndrome caused by a PAX2 mutation. Clin Kidney J.6:41-413.

10. Corapi KM, Chen JL, Balk EM, Gordon CE. Bleeding complications of native kidney biopsy: a systematic review and meta-analysis. Am J Kidney Dis. 2012;60:62-73.

11. Harris PC, Rossetti S. Molecular diagnostics for autosomal dominant polycystic kidney disease. Nat Rev Nephrol. 2010;6:197-206.

12. Rossetti S, Harris PC. Genotype-phenotype correlations in autosomal dominant and autosomal recessive polycystic kidney disease. J Am Soc Nephrol. 2007;18:1374-80.

13. Adalat S, Bockenhauer D, Ledermann SE, Hennekam RC, Woolf AS. Renal malformations associated with mutations of developmental genes: messages from the clinic. Pediatr Nephrol. 2010;25:2247-55.

14. Mallett A, Fowles LF, McGaughran J, Healy H, Patel C. A multidisciplinary renal genetics clinic improves patient diagnosis. Med J Aust. 2016;204:58-9.

15. Jacob HJ, Abrams K, Bick DP, Brodie K, Dimmock DP, Farrell M, et al. Genomics in clinical practice: lessons from the front lines. Sci Trans/ Med. 2013;5:194cm5.

16. Shashi V, McConkie-Rosell A, Rosell B, Schoch K, Vellore K, McDonald M, et al. The utility of the traditional medical genetics diagnostic evaluation in the context of nextgeneration sequencing for undiagnosed genetic disorders. Genet Med. 2014;16:176-82. 17. Monroe GR, Frederix GW, Savelberg SM, de Vries TI, Duran KJ, van der Smagt JJ, et al. Effectiveness of whole-exome sequencing and costs of the traditional diagnostic trajectory in children with intellectual disability. Genet Med. 2016;18:949-56. 
1 18. Manolio TA, Chisholm RL, Ozenberger B, Roden DM, Williams MS, Wilson R, et al.

2 Implementing genomic medicine in the clinic: the future is here. Genet Med. 2013;15:258-

367.

4

5 
2 Table 1: Clinical features and reason for referral

3

\begin{tabular}{|l|l|}
\hline Familial haematuria & $30(37.5 \%)$ \\
\hline Cystic kidney disease & $25(31.3 \%)$ \\
\hline $\begin{array}{l}\text { Congenital abnormality of kidney / urinary tract } \\
(\text { CAKUT) }\end{array}$ & $7(8.8 \%)$ \\
\hline Tubulopathy / electrolyte disturbance & $7(8.8 \%)$ \\
\hline Ciliopathy syndrome & $4(5 \%)$ \\
\hline Tuberose sclerosis complex (TSC) & $3(3.8 \%)$ \\
\hline Congenital nephrotic syndrome & $2(2.5 \%)$ \\
\hline Early onset hypertension & $2(2.5 \%)$ \\
\hline
\end{tabular}

4

5 
2 Table 2: Known molecular genetic diagnosis prior to clinic

3

\begin{tabular}{|l|l|l|}
\hline Clinical Diagnosis of \\
\hline Diabetes insipidus & Gene & $\begin{array}{l}\text { Number } \\
\text { probands }\end{array}$ \\
\hline Joubert syndrome & AVPR2 & 3 \\
\hline Joubert syndrome with nephronophthisis & CEP290 & 1 \\
\hline Autosomal dominant Alport syndrome & COL4A3 & 1 \\
\hline X-linked Alport syndrome & COL4A5 & 1 \\
\hline $\begin{array}{l}\text { Renal cysts and diabetes syndrome } \\
\text { (RCAD) }\end{array}$ & HNF1B & 1 \\
\hline $\begin{array}{l}\text { Donnai-Barrow syndrome } \\
\text { Autosomal Dominant Tubulointerstitial } \\
\text { Kidney Disease (ADTKD) }\end{array}$ & MUC1 & 1 \\
\hline $\begin{array}{l}\text { Oro-facial-digital syndrome } \\
\text { Autosomal recessive polycystic kidney } \\
\text { disease (ARPKD) }\end{array}$ & PKHD1 & 1 \\
\hline $\begin{array}{l}\text { Autosomal Dominant Tubulointerstitial } \\
\text { Kidney Disease (ADTKD) }\end{array}$ & REN & 1 \\
\hline $\begin{array}{l}\text { Autosomal Dominant Tubulointerstitial } \\
\text { Kidney Disease (ADTKD) }\end{array}$ & UMOD & 5 \\
\hline
\end{tabular}

4 
2 Table 3: Confirmed clinical and molecular diagnoses made following a clinic visit 3

\begin{tabular}{|c|c|c|c|}
\hline Reason for Referral & Clinical Diagnosis & Gene & $\begin{array}{l}\text { Number of } \\
\text { probands } \\
\text { confirmed }\end{array}$ \\
\hline $\begin{array}{l}\text { Suspected ciliopathy } \\
\text { syndrome }\end{array}$ & Joubert syndrome & $C C 2 D 2 A$ & 1 \\
\hline $\begin{array}{l}\text { Suspected ciliopathy } \\
\text { syndrome }\end{array}$ & Joubert syndrome & CEP290 & 1 \\
\hline Tubulopathy & Bartter's syndrome & $C L C N K B$ & 1 \\
\hline Familial haematuria & $\begin{array}{l}\text { Autosomal } \\
\text { dominant Alport } \\
\text { syndrome / Thin } \\
\text { basement } \\
\text { membrane } \\
\text { nephropathy }\end{array}$ & COLAA3 & 3 \\
\hline Familial haematuria & $\begin{array}{l}\text { Autosomal } \\
\text { dominant Alport } \\
\text { syndrome / Thin } \\
\text { basement } \\
\text { membrane } \\
\text { nephropathy }\end{array}$ & COLAA4 & 4 \\
\hline Familial haematuria & $\begin{array}{l}\text { X-linked Alport } \\
\text { syndrome }\end{array}$ & COLAA5 & $9 *$ \\
\hline $\begin{array}{l}\text { Congenital nephrotic } \\
\text { syndrome }\end{array}$ & $\begin{array}{l}\text { Congenital } \\
\text { Nephrotic } \\
\text { syndrome }\end{array}$ & NPHS1 & 1 \\
\hline CAKUT & $\begin{array}{l}\text { Renal coloboma } \\
\text { syndrome }\end{array}$ & $P A X 2$ & 1 \\
\hline Cystic kidney disease & $\begin{array}{l}\text { Autosomal } \\
\text { dominant }\end{array}$ & $P K D 1$ & 4 \\
\hline
\end{tabular}




\begin{tabular}{|l|l|l|l|}
\hline & $\begin{array}{l}\text { polycystic kidney } \\
\text { disease }\end{array}$ & & \\
\hline Tubulopathy & $\begin{array}{l}\text { Hypomagnesemia } \\
\text { with secondary } \\
\text { hypocalcemia }\end{array}$ & TRPM6 & 1 \\
\hline
\end{tabular}

1

2 *Includes one proband with a VUS (which segregated with phenotype) in COL4A5

3

4

5

6 